\title{
ACCURACY IN TIMBER ESTIMATING
}

\author{
By R. D. LOOMIS
}

\author{
Brompton Pulp and Paper Company, Limited, Nipigon, Ontario
}

$A$ LL estimates of volume of standing trees both for inventory and operating purposes for the Brompton Pulp and Paper Company on their limits in the Thunder Bay District of Ontario are being made from aerial photos with a minimum of ground work.

During July and August of this year a tract of 2,700 acres in the Shadow Creek Watershed near this Company's Camp 32 was estimated twice. Each estimate was based on a different method of cruising but in each case a forest type map was compiled from aerial photographs before commencing the field work. The purpose in making two estimates of the same area was to obtain a comparison of the accuracy and cost of the two methods of doing field work -one method being similar to the usual way of cruising while the other was more in keeping with our present practice of obtaining type boundaries and timber classification from aerial photographs.

The first estimate was made up from a five per cent cruise run the usual way-base lines two miles apart and $1 / 2$ chain strip lines from one base line to the other at ten chain intervals.

The second estimate was compiled from the information on not more than a one per cent field check and the aerial type map. The field check consisted of tallying on the ground one quarter acre plots selected beforehand from a careful examination of the photos. The plots were selected so as to obtain an average volume per acre of the whole stand contained within the boundaries of any particular type as shown on the aerial type map. In locating these plots no attempt was made to run cruise lines the usual way. The spots selected for the plots were marked on the photos and map and these were used without difficulty in locating the plot on the ground.

The latter method of field checking allows greater scope for examining the tract as to logging possibilities and quality of timber in each type. Also the cost of making an estimate is very much lessened-in this instance, 34 man days of field work as against over 60 man days by the base line-cruise line method. mates.

The following is a comparison of the summary by cords of the two esti-

\begin{tabular}{|c|c|c|c|c|c|}
\hline \multicolumn{6}{|c|}{ Base Line Cruise Line Method } \\
\hline SPRUCE & BALSAM & J. PinI & ALL SOFTWOODS & ALL HARDWOODS & Alll SPECIES \\
\hline 34,499 & 689 & 793 & 35,981 & 7,335 & 43,316 \\
\hline \multicolumn{6}{|c|}{ Selected Plot System } \\
\hline 36,837 & 725 & 1070 & 38,632 & 11,880 & 50,512 \\
\hline $2,3,38$ & 36 & 277 & $\begin{array}{c}\text { DifferenC } \\
2,651\end{array}$ & 4,545 & 7,196 \\
\hline
\end{tabular}


The selected plot estimate is above the other estimate by about 7 per cent in total for all softwoods and 17 per cent above for all species. However the following check against wood cut and scaled indicated that the selected plot estimate is nearer to the actual cutable wood.

Last autumn the boundaries of two areas within the tract were blazed and marked for the purpose of checking the estimates against the amount of wood cut and scaled. Recently the cutting and scaling on one of these areas was completed. A comparison using the cut and scaled wood as 100 per cent is shown below.

\begin{tabular}{lcccc} 
& \multicolumn{2}{c}{ Estimate Based } & Estimate Based & \\
WoOd Cut & ON Strip Line & ON Selected & \\
ANd Scaled & Method & Difference & PlOT System & Difference \\
513.74 net cds & $583.3 \mathrm{cds}$. & $13.5 \%$ & $507.8 \mathrm{cds}$. & $=1.2 \%$
\end{tabular}

This check indicates that our method of obtaining an estimate based on interpreting aerial photos with a field check of a few selected plots is going to work out satisfactorily. It happens that the check on this small area is much more accurate than running costly base lines and cruise lines.

The point in favor of this check is that in order to obtain the same degree of accuracy in timber estimating the rule is to increase the percentage of area cruised as the unit of area or tract decreases. In other words it is harder to obtain an accurate estimate on a small tract than a large one. The above check was on a unit of anly 18.4 acres. With results such as this on small units and with a comparatively small per cent of field checking we should be able to assume that on the large tract the accuracy will be well within an allowable error of plus or minus 10 per cent even if this particular check happens to be unusual. 